\title{
Correction to: Innovation pathway to profitability: the role of entrepreneurial orientation and marketing capabilities
}

\author{
S. Arunachalam ${ }^{1} \cdot$ Sridhar N. Ramaswami ${ }^{2,3} \cdot$ Pol Herrmann $^{2,4} \cdot$ Doug Walker $^{5}$
}

Published online: 19 February 2018

(C) Academy of Marketing Science 2018

Correction to: J. of the Acad. Mark. Sci. https://doi.org/10.1007/s11747-017-0574-1

The original version of this article unfortunately contained a mistake. The equation under "Profile deviation analysis" section should be:

Deviation $=\sqrt{ } \sum_{\mathrm{j}=1}^{2}\left(X_{s j}-\overline{X_{i j}}\right)^{2}$

The original article has been corrected.

The online version of the original article can be found at https://oi.org/ 10.1007/s11747-017-0574-1

S. Arunachalam

s_arunachalam@isb.edu

Sridhar N. Ramaswami

sramaswa@iastate.edu

Pol Herrmann

pol@iastate.edu

Doug Walker

dmwalker@ksu.edu

1 Indian School of Business, Gachibowli, Hyderabad 500032, India

2 Ivy College of Business, Iowa State University, 3216 Gerdin Business Building, Ames, IA 50011-1350, USA

3 Indian School of Business, Hyderabad, India

4 Tecnológico de Monterrey, EGADE Business School, San Pedro Garza García, Mexico

5 Kansas State University, 201 A Calvin Hall, Manhattan, KS 66506, USA 